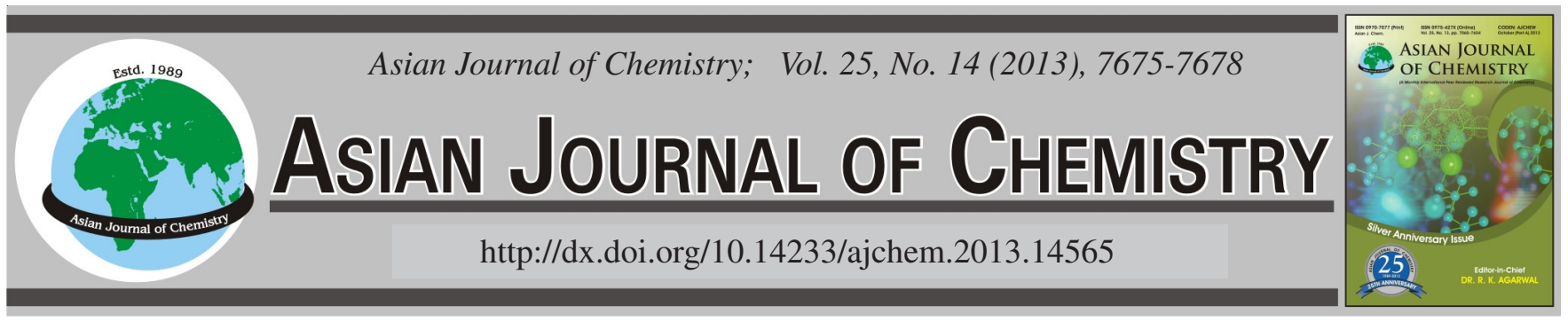

\title{
Catalytic Synthesis of Butyl Isovalerate by Brønsted Acidic Ionic Liquid under Microwave Irradiation
}

\author{
Du Huan, He Yanfei, Tan Zhongein and XiaOXiang Han*
}

Department of Applied Chemistry, College of Food Science \& Biotechnology Engineering, Zhejiang Gongshang University, Hangzhou, 310035, P.R. China

*Corresponding author: Tel: +86 571 88071024-7581; E-mail: hxx74@126.com; han-xx74@163.com

(Received: 14 September 2012;

Accepted: 8 July 2013)

AJC-13785

\begin{abstract}
Butyl isovalerate was synthesized from isovaleric acid and butanol with ionic liquid as catalysts under microwave irradiation. The systematic study was investigated including of the effects of molar ratio of acid to alcohol, microwave power, amount of catalyst, microwave time and microwave temperature on the process. The optimum operation conditions were as follows: $n$ (butanol): $n$ (isovaleric acid) $=1.6: 1$, microwave power $500 \mathrm{~W}$, amount of catalyst of $6 \mathrm{wt} \%$ to isovaleric acid, microwave time of $0.5 \mathrm{~h}$ and microwave temperature of $110{ }^{\circ} \mathrm{C}$. The yield of butyl isovalerate could reach $92.1 \%$ under the optimal operation conditions mentioned above. The excellent durability and recycle ability of ionic liquids were also addressed even after five times reused.
\end{abstract}

Key Words: Ionic liquid, Butyl isovalerate, Esterification, Microwave irradiation.

ᄂ - - - - - - - - - - - - - - - - - - - - - - - - -

\section{INTRODUCTION}

Butyl isovalerate, a transparent with colourless or tiny yellow colour liquid, is of fragrance feature of banana and blue chess. It's common used as perfumes for the preparation of dairy products and cheese and also as flavor chemicals, solvents and precursors for pharmaceuticals and fine chemicals ${ }^{1}$. In traditional industries, butyl isovalerate is generally synthesized from isovaleric acid and butanol by using homogeneous catalysts such as $\mathrm{H}_{2} \mathrm{SO}_{4}$. However, sulphuric acid suffers from inherent drawbacks such as equipment corrosion, more byproducts, environmental hazards, difficulty in catalyst recovery and reuse ability. These make this process with environmentally questionable. Therefore, the development of heterogeneous catalysts systems aimed at overcoming these limitations have proven to be a significant task. Supported heteropoly acid $^{2}$, ion exchange resin ${ }^{3}$, molecular sieve ${ }^{4}$ and lipase ${ }^{5}$ have been carried out on the esterification of isovalerate ester. However, all these processes and catalysts have their own disadvantages such as higher cost, low activity, easy deactivation, difficult separation from the products and catalyst recyclability.

During the past few decades, ionic liquids (ILs) have received considerable attention as eco-friendly and effective reaction catalyst for a wide variety of organic reaction and other applications in chemistry due to its adjustable physical and chemical properties ${ }^{6,7}$. Indeed, ionic liquid especially acidic-functionalized ionic liquids show special advantages: no measurable vapor pressure, excellent thermal stability, potential recover ability, recycle ability and are able to dissolve compounds with varying polarity ${ }^{8-10}$. So applications of ionic liquids have been extensively studied with high yields, among which esterification is hot topic. Since then, a series of reports regarding synthesis of ester using acidic-functionalized ionic liquids as catalysts have been published ${ }^{1-13}$. Mostly all mentioned reactions have been carried out using reactors accompanied with traditional heat-transfer equipment. However, the reaction time is long.

Microwave irradiation becomes a new green technology instead of conventional heating. It is an internal heated method and demonstrates many characteristics i.e., fast heating rate with no lag effects, lower energy consumption, easy to operate and less pollution. In many cases, microwave-assisted chemical reactions have showed amazing accelerations, higher yields and selectivity and higher product purities under milder reaction conditions ${ }^{14,15}$. Microwave heating has also been applied to esterification, besides being environmentally friendly, it is also marked by a considerable reduction in reaction time ${ }^{16,17}$. The aim of the present work is to establish the optimal conditions for the esterification of isovaleric acid with butanol in a laboratory prepared Brønsted acid functionalized ionic liquid catalyst. Additionally, the stability and reuse performance of catalyst was also examined. 


\section{EXPERIMENTAL}

Catalyst preparation and characterization: Brønsted acidic ionic liquids were prepared and characterized by IR, NMR, TG and acidity determination in the laboratory following the procedure outlined in literature ${ }^{13,18}$. All the chemicals were research grade and were used without further purification unless otherwise stated. The catalysts were abbreviated as: $\left[\mathrm{HSO}_{3}-\right.$ pmim $] \mathrm{HSO}_{4},\left[\mathrm{HSO}_{3}\right.$-pmim]PTSA, $\left[\mathrm{HSO}_{3}\right.$-pmim $] \mathrm{H}_{2} \mathrm{PO}_{4}$ and $\left[\mathrm{HSO}_{3}\right.$-pmim $] \mathrm{COOCF}_{3}, \mathrm{HSO}_{3}$-pmim = 1-methyl-3- (propyl3-sulfonic group) imidazole.

Activity testing: In a typical procedure, isovaleric acid (0.1 mol, $10.21 \mathrm{~g})$, butanol (0.16 mol, $11.85 \mathrm{~g})$ and ionic liquid $(0.78 \mathrm{~g})$ were added into a three-necked round bottom flask. The reactions were carried out in microwave synthesis system equipped with a magnetic stirrer and a water-cooled condenser. The reaction mixture was heated to appropriate temperature for desired time with certain microwave power. Upon completion, the reaction mixture was cooled to room temperature and the layers separated. The upper layer was ester. The lower layer consisting of the ionic liquid was reused in a further run. Chemical analysis of the products was performed by gas chromatography Agilent 6890N GC, equipped with a FID detector and HP-5 capillary column. Reactants and products were identified by comparison with authentic samples. Methyl laurate was used as an internal standard.

\section{RESULTS AND DISCUSSION}

Comparison of activity of the four ionic liquid catalysts: The acidity strength order of ionic liquids is consistent with their activity order in some acid-catalyzed reactions. It is known that anions have strong interactions with the proton donated from sulfonic acid. The anion is likely to serve as available acid sites. Hence the acidities and catalytic activities of ionic liquids always depend on the kinds of anions. The catalytic performances of ionic liquid with different anion at certain conditions were also given in Table-1. From Table-1, we could find that ionic liquid with $\mathrm{HSO}_{4}{ }^{-}$showed the best catalytic activity for esterification with $92.1 \%$ yield of butyl isovalerate. Ionic liquid containing $\mathrm{H}_{2} \mathrm{PO}_{4}^{-}$and $\mathrm{CF}_{3} \mathrm{COO}^{-}$ anions showed poorer activity as compared to the above. Such a high activity of Brønsted ionic liquid with $\mathrm{HSO}_{4}{ }^{-}$anion has also been reported in the Fischer esterification reaction with other ionic liquids ${ }^{19}$. The order of esterification activity for ionic liquids with different anions was $\left[\mathrm{HSO}_{4}^{-}\right]>\left[p-\mathrm{CH}_{3} \mathrm{C}_{6} \mathrm{H}_{4} \mathrm{SO}_{3}{ }^{-}\right.$ ]$>\left[\mathrm{H}_{2} \mathrm{PO}_{4}^{-}\right]>\left[\mathrm{CF}_{3} \mathrm{COO}^{-}\right]$, which was in excellent agreement with their acidity order ${ }^{18}$. Detailed investigations to optimize various reaction parameters were conducted using $\left[\mathrm{HSO}_{3}-\right.$ pmim] $\mathrm{HSO}_{4}$ as catalyst since it was also less toxic and cost effective besides showing high product selectivity.
Effect of ratio of butanol to isovaleric acid: Butanol is a major component in the pre-treatment process via esterification reaction. Its molar ratio significantly affects the conversion of isovaleric acid to butyl isovalerate during the course of reaction. The molar ratio of butanol to isovaleric acid varied from 1.2:1 to 2.2:1, Fig. 1 revealed the ratio effect and it is observed that as the amount of butanol increased, the yield of butyl isovalerate increased and reached a maximum of $92.1 \%$ with butanol to isovaleric acid mole ratio of 1.6:1. According to the chemical equilibrium principle, the excess of one of the reactants made the equilibrium shifting towards the products side. However, when the mole ratio of butanol to isovaleric acid exceeded 1.6:1, the yield of butyl isovalerate decreased. It might be due to dilution phenomenon of the isovaleric acid and $\left[\mathrm{HSO}_{3}\right.$-pmim] $\mathrm{HSO}_{4}$ with excess butanol.

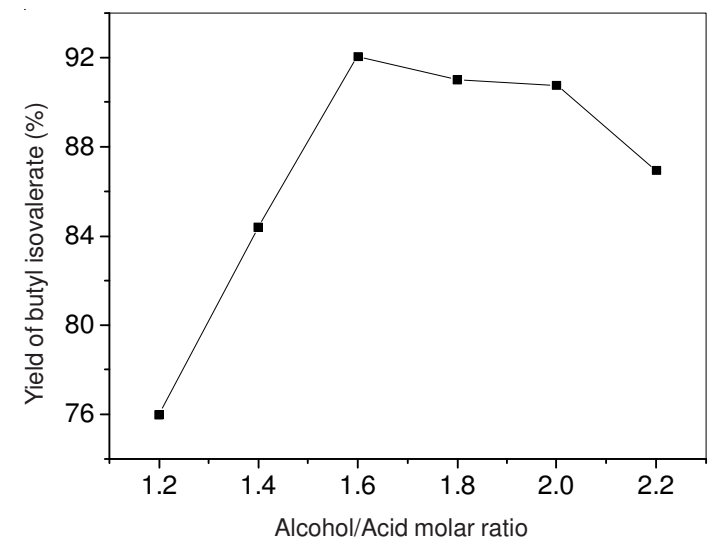

Fig. 1. Esterification reaction of butanol with isovaleric acid under different molar reactant ratios

Effect of microwave power: For the purpose of compare the effect of microwave power on the esterification rate, butyl isovalerate was synthesized under different power of microwave irradiation. The results were shown in Fig. 2. It could be found that microwave power had a great influence on yield of butyl isovalerate. The yield of butyl isovalerate increased with increasing microwave power. When the microwave power was $500 \mathrm{~W}$, the highest yield of butyl isovalerate was $92.1 \%$ in $0.5 \mathrm{~h}$ at $110^{\circ} \mathrm{C}$. However, when the microwave power exceeded $500 \mathrm{~W}$, the yield of butyl isovalerate decreased. The reason was that the reaction was not complete with low microwave power owing to fewer amounts of the excited molecules. While the yield decreased with high microwave power because the collisions between the reactant molecules were too violent ${ }^{17}$ and the velocity of side effects also greatly accelerated. Additionally, high power of microwave accumulated energy over a period of time and released it quickly, thus increasing the instantaneous temperature vaporized partial butanol. It was not beneficial for esterification.

TABLE-1

RESULTS OF DIFFERENT IONIC LIQUIDS ON THE YIELD OF BUTYL ISOVALERATE

\begin{tabular}{|c|c|c|c|c|c|}
\hline Ionic liquid & $\begin{array}{c}\text { Alcohol/acid mole } \\
\text { ratio }\end{array}$ & $\begin{array}{c}\text { Amount of catalyst } \\
\text { (wt \%) }\end{array}$ & $\begin{array}{l}\text { Microwave power } \\
\text { (W) }\end{array}$ & $\begin{array}{l}\text { Reaction time } \\
\text { (min) }\end{array}$ & $\begin{array}{l}\text { Yield } \\
(\%)\end{array}$ \\
\hline$\left[\mathrm{HSO}_{3}-\mathrm{pmim} \mathrm{HSO}_{4}\right.$ & $1.6: 1$ & 6 & 500 & 30 & 92.1 \\
\hline$\left[\mathrm{HSO}_{3}\right.$-pmim]PTSA & $1.6: 1$ & 6 & 500 & 30 & 91.3 \\
\hline$\left[\mathrm{HSO}_{3}-\mathrm{pmim}\right] \mathrm{H}_{2} \mathrm{PO}_{4}$ & $1.6: 1$ & 6 & 500 & 30 & 43.8 \\
\hline$\left[\mathrm{HSO}_{3}-\mathrm{pmim}\right] \mathrm{COOCF}_{3}$ & 1.6:1 & 6 & 500 & 30 & 39.2 \\
\hline
\end{tabular}




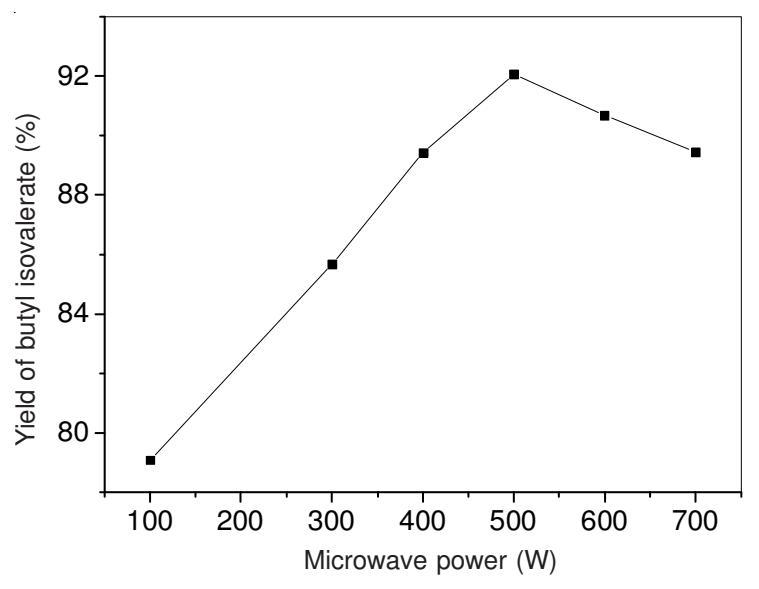

Fig. 2. Esterification reaction of butanol with isovaleric acid under different microwave power

Effect of amount of [ $\mathrm{HSO}_{3}$-pmim] $\mathrm{HSO}_{4}$ : The amount of ionic liquids played an important role during the esterification reaction. Finding the optimal amount of catalyst had the priority among all reaction parameters. Fig. 3 showed the effect of the amount of ionic liquids on the yield of butyl isovalerate. As the amount of ionic liquids increased, the conversion of isovaleric acid also increased. When $6 \mathrm{wt} \%$ of $\left[\mathrm{HSO}_{3}-\right.$ pmim] $\mathrm{HSO}_{4}$ was added, $92.1 \%$ of isovaleric acid was converted into butyl isovalerate in $0.5 \mathrm{~h}$. There were enough active sites for the reaction when the amount of catalyst was 6 wt $\%$. However, the yield of butyl isovalerate decreased slightly when the amount of catalyst exceeded $6 \mathrm{wt} \%$. It might be due to the growth of side effect resulted from the increasing amount of ionic liquid meant increasing the acidity of the reaction system. Moreover, it was also ascribed to the solubility of ionic liquid. The ionic liquid can dissolve in butanol, but had little solubility in butyl isovalerate. The solubility of ionic liquid was also restricted by the degree of ester and butanol mixing. Considering the conversion of isovaleric acid, the product distribution and less cost effective, the optimal amount of $\left[\mathrm{HSO}_{3}\right.$-pmim $] \mathrm{HSO}_{4}$ should be around $6 \mathrm{wt} \%$.

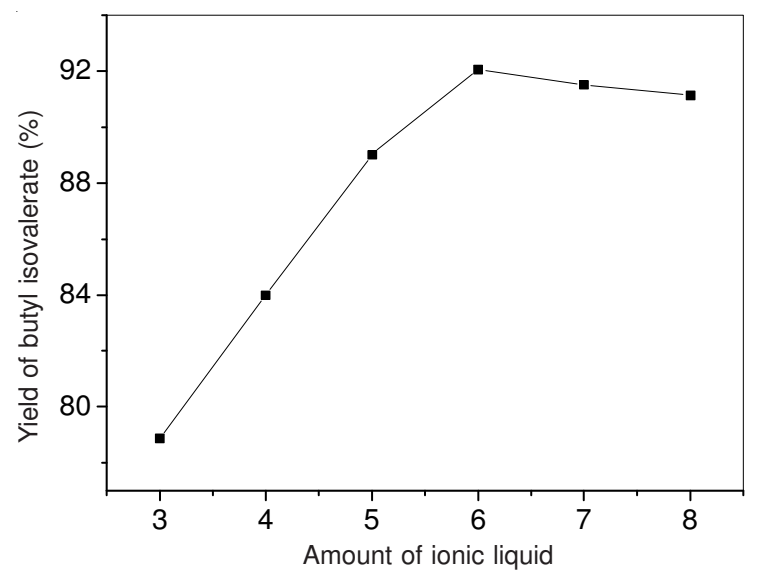

Fig. 3. Esterification reaction of butanol with isovaleric acid under different amount of catalysts

Effect of microwave time: Generally, extending reaction time could make the reaction more completely. The influence of reaction time on the esterification of isovaleric acid and butanol was determined by using $6 \mathrm{wt} \%$ catalyst, a molar ratio of butanol to isovaleric acid 1.6:1 and a temperature of $110^{\circ} \mathrm{C}$ under $500 \mathrm{~W}$ microwave radiation. As we can see in Fig. 4, we could divide the reaction into three phases approximately according to the reaction trend. In the first phase, the yield of butyl isovalerate reached $90 \%$ rapidly within $25 \mathrm{~min}$. It was because excess of butanol to react with isovaleric acid make the esterification more easily. In the second phase, the process of the reaction became slowly from 25 to $30 \mathrm{~min}$ and the reaction approached equilibrium in this phase. The best yield of butyl isovalerate $(92.1 \%$ ) was obtained around $0.5 \mathrm{~h}$. In the last phase, yield of butyl butyrate decreased slightly instead of an upward trend when the reaction time was prolonged. This was because esterification was a reversible reaction, leading the product partially hydrolyzed when reaction time was too long. Therefore, the optimal reaction time should be around $0.5 \mathrm{~h}$.

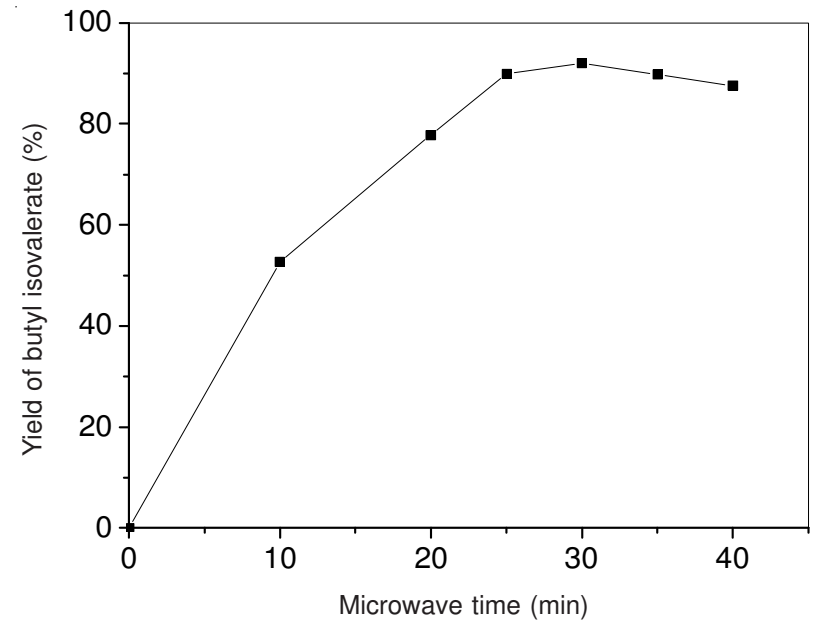

Fig. 4. Esterification reaction of butanol with isovaleric acid under different microwave time

Effect of microwave temperature: We also examined the effect of reaction temperature on the esterification of butyl isovalerate, the results were shown in Fig. 5. When the reaction temperature was $90^{\circ} \mathrm{C}, 78.2 \%$ of isovaleric acid was converted into butyl isovalerate. Yield of butyl isovalerate increased with a rise in temperature, reaching a maximum $92.1 \%$ at $110{ }^{\circ} \mathrm{C}$. Then, the yield declined gradually with increasing the temperature. The reason was that more successful collisions occurred at high temperature, it could contribute to the enhancement of reaction rate and the yield of butyl isovalerate. When the reaction temperature exceeded $110^{\circ} \mathrm{C}$ even above the boiling point of butanol $\left(117.7^{\circ} \mathrm{C}\right)$, butanol was easily vaporized, the successful collision possibility reduced and the yield of butyl isovalerate decreased.

Recycling of ionic liquid [ $\mathrm{HSO}_{3}$-pmim] $\mathrm{HSO}_{4}$ : The main advantage of the ionic liquid catalysts was that it could be recyclable for further use. To make this method more suitable, we examined the reusability of catalyst. $\left[\mathrm{HSO}_{3}-\mathrm{pmim}\right] \mathrm{HSO}_{4}$ was investigated by performing several runs under the optimized reaction conditions determined above. After each cycling reaction, the ionic liquid was extracted with toluene and vacuum dried for $5 \mathrm{~h}$ at $120^{\circ} \mathrm{C}$. After vacuum drying, the $\left[\mathrm{HSO}_{3}\right.$-pmim $] \mathrm{HSO}_{4}$ was assessed by ${ }^{1} \mathrm{H}$ NMR spectroscopy, which showed no traces of reactants or products. The results from Table-2 showed that $\left[\mathrm{HSO}_{3}\right.$ - $\mathrm{pmim}^{-} \mathrm{HSO}_{4}$ could be reused 


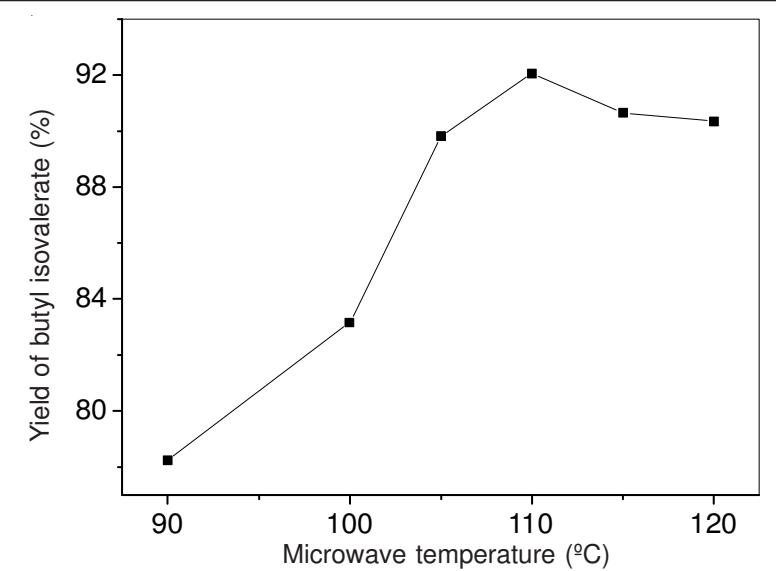

Fig. 5. Esterification reaction of butanol with isovaleric acid under different microwave temperature

\begin{tabular}{cccc}
\multicolumn{5}{c}{ TABLE-2 } \\
CATALYST RECYCLING OF ESTERIFICATION \\
OF ISOVALERIC ACID & WITH BUTANOL \\
\hline Run & Yield $(\%)$ & Run & Yield $(\%)$ \\
\hline 1 & 92.1 & 4 & 87.7 \\
2 & 91.0 & 5 & 86.4 \\
3 & 89.7 & - & - \\
\hline
\end{tabular}

five times without significant loss of activity. The yield of butyl isovalerate was still as high as $86.4 \%$, which indicated that as the catalyst for esterification, $\left[\mathrm{HSO}_{3}-\mathrm{pmim}\right] \mathrm{HSO}_{4}$ has excellent reusability. The slight decrease of yield was probably due to the slight deactivation of ionic liquid.

\section{Conclusion}

In the reaction, the process conditions were optimized upon varying several reaction parameters. The optimum conditions were obtained as follows: $6 \mathrm{wt} \%\left[\mathrm{HSO}_{3}-\mathrm{pmim}\right] \mathrm{HSO}_{4}$, $500 \mathrm{~W}$ microwave power and 1.6:1 mole ratio butanol to isovaleric acid at $110^{\circ} \mathrm{C}$ and atmospheric pressure, a maximum of $92.1 \%$ yield of the esterification was achieved in $0.5 \mathrm{~h}$ under microwave irradiation. The reaction time was significantly reduced. The fact indicated that the friendly catalyst $\left[\mathrm{HSO}_{3}\right.$-pmim $] \mathrm{HSO}_{4}$ showed excellent catalytic activity, stability and reusability in this case and we received a satisfactory yield for esterification in short time. Therefore, an efficient and environmentally friendly catalyst and heating method were provided for the synthesis of butyl isovalerate.

\section{REFERENCES}

1. G.T. Ling, Food Additives Handbook, Beijing: Chemical Industry Press, edn. 2, p. 316 (1997)

2 F.J. Zhang and S.L. Sheng, Liquor-Making Sci. Technol., 153, 9 (2007) (in Chinese).

3 X. Zhang and J.H. Li, HeBei Chem. Ind., 34, 57 (2011) (in Chinese).

4 M.H. Li, D.W. Yang, Y. Yang and J. Wang, Adv. Fine Petrochem., 6, 22 (2005) (in Chinese).

5 G.V. Chowdary, M.N. Ramesh and S.G. Prapulla, Process Biochem., 36, 331 (2001).

6 T. Welton, Chem. Rev., 99, 2071 (1999).

7 L.A. Blanchard, D. Hancu, E.J. Beckman and J.F. Brennecke, Nature, 399, 28 (1999).

8 S.G. Cull, J.D. Holbrey, V. Vargas-Mora, K.R. Seddon and G.J. Lye, Biotechnol. Bioeng., 69, 227 (2000)

9 R. Sheldon, Chem. Commun., 23, 2399 (2001).

10 N.V. Plechkova and K.R. Seddon, Chem. Soc. Rev., 37, 123 (2008).

11 G. Pralhad, G. Gigi and D. Jagannath, J. Mol. Catal., 279, 182 (2008).

12 L. Zhang, M. Xian, Y.C. He, L.Z. Li, J.M. Yang, S.T. Yu and X. Xu, Bioresour. Technol., 100, 4368 (2009).

13 X.X. Han and L.X. Zhou, Chem. Eng. J., 172, 459 (2011).

14 A. da la Hoz, A. Diaz-Ortiz and A. Moreno, Chem. Soc. Rev., 34, 164 (2005).

15 C.O. Kappe, Angew. Chem. Int. Ed., 43, 6250 (2004).

16 B. Major, I. Kelemen-Horváth, Z. Csanádi, K. Bélafi-Bakó and L. Gubicza, Green Chem., 11, 614 (2009).

17 X. Liao, G.S.V. Raghavan and V.A. Yaylayan, Tetrahedron Lett., 43, 45 (2002).

18 X.D. Wu, X.X. Han, L.X. Zhou and A. Li, Indian J. Chem., 51B, 791 (2012).

19 H. Xing, T. Wang, Z. Zhou and Y. Dai, Ind. Eng. Chem. Res., 44, 4147 (2005). 